刘子涵,黄方园,黎景来, 张鹏,杨宝平, 丁瑞霞, 聂俊峰, 贾志宽. 覆盖模式对旱作农田土壤微生物多样性及群落结构的影响.生态学报, 2021,41 (7) :2750- 2760 .

Liu Z H, Huang F Y, Li J L, Zhang P, Yang B P, Ding R X, Nie J F, Jia Z K. Effects of farmland mulching patterns on soil microbial diversity and community structure in dryland.Acta Ecologica Sinica, 2021,41(7) :2750-2760.

\title{
覆盖模式对旱作农田土壤微生物多样性及群落结构的 影响
}

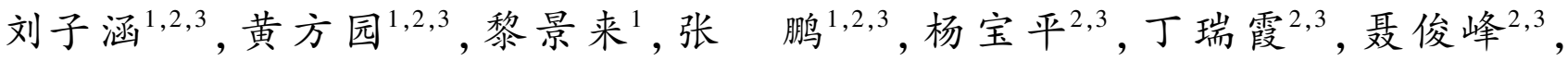
贾志宽 $1,2,3, *$

1 西北农林科技大学农学院, 咸阳 712100

2 中国旱区节水农业研究院, 咸阳 712100

3 农业部西北黄土高原作物生理生态与耕作重点实验室, 咸阳 712100

摘要:土壤微生物是表征土壤质量的敏感指标, 采用 Illumina HiSep 技术分析不同覆盖方式对半湿润易旱区农田土壤微生物群 落结构及多样性的影响, 以期从微生物的角度评价农田不同覆盖措施对土壤质量的影响。设 3 种覆盖模式: 平作塑料薄膜覆盖 $(P) 、$ 平作秸秆覆盖 $(S)$ 和垄膜沟播覆盖 $(R)$, 以平作不覆盖为对照 $(\mathrm{CK})$, 研究不同覆盖模式下土壤微生物群落变化, 分析各土 壤理化因子与微生物群落之间的关系。研究结果表明各覆盖处理显著改变了土壤微生物的群落结构和多样性。所有土壤样品 中, 细菌群落的优势菌门是变形菌门 (Proteobacteria)、酸杆菌门 (Acidobacteria)、放线菌门 (Actinobacteria), 丰度分别为 $29.69 \%$ 、 $28.28 \%$ 和 $20.76 \%, \mathrm{CK}$ 处理下较高的土壤 $\mathrm{pH}$ 和低 $\mathrm{NO}_{3}-\mathrm{N}$ 含量抑制了土壤中酸杆菌门 (Acidobacteria) 的生长繁殖, 而放线菌门 (Actinobacteria) 相对丰度为所有处理中最高。真菌群落的优势菌门是子囊菌门 (Ascomycota)、担子菌门 (Basidiomycota), 丰度 分别为 $59.65 \%$ 和 $20.96 \%, \mathrm{~S}$ 处理下过低的土壤温度抑制了担子菌门 (Basidiomycota) 生长和繁殖, 其相对丰度为所有处理中最 低。与 $\mathrm{CK}$ 相比, $\mathrm{P}$ 和 $\mathrm{R}$ 处理显著提高土壤细菌的多样性和丰富度 $; \mathrm{S}$ 和 $\mathrm{R}$ 处理下土壤真菌多样性和丰富度显著增加, 而 $\mathrm{P}$ 处 理的土壤真菌多样性和丰富度均无显著差异。斯皮尔曼相关分析表明土壤细菌多样性主要受土壤含水量 (SM) 和硝态氮含量 $\left(\mathrm{NO}_{3}-\mathrm{N}\right)$ 影响, 而土壤真菌多样性主要受土壤温度 $(\mathrm{ST})$ 、全氮 $(\mathrm{TN})$ 和硝态氮含量 $\left(\mathrm{NO}_{3}-\mathrm{N}\right)$ 影响; $\mathrm{RDA}$ 分析表明微生物群落结 构的变化主要受 $\mathrm{SM} 、 \mathrm{ST} 、 \mathrm{NO}_{3}-\mathrm{N}$ 和 TN 含量的影响。总的来说, $\mathrm{R}$ 处理下土壤细菌和真菌的多样性和丰富度较 CK 处理显著提 高,该处理下土壤中担子菌门 (Basidiomycota) 和球囊菌 (Glomeromycota) 相对丰度为所有处理中最高,两者分别形成的外生菌根 和从生菌根不但促进了根部养分的吸收, 而且提高了作物的抗逆性, 且结果证明该处理的作物产量为最高, 因此在半湿润旱作 区推荐采用垄膜沟播覆盖种植方式。

关键词: 农田覆盖;微生物群落; 高通量测序; 土壤理化性质

\section{Effects of farmland mulching patterns on soil microbial diversity and community structure in dryland}

LIU Zihan ${ }^{1,2,3}$, HUANG Fangyuan ${ }^{1,2,3}$, LI Jinglai ${ }^{1}$, ZHANG Peng ${ }^{1,2,3}$, YANG Baoping ${ }^{2,3}$, DING Ruixia ${ }^{2,3}$, NIE Junfeng ${ }^{2,3}$, JIA Zhikuan ${ }^{1,2,3 *}$

1 College of Agronomy, Northwest A\&F University, Xianyang 712100, China

2 The Chinese Institute of Water-saving Agriculture, Xianyang 712100, China

3 Key Laboratory of Crop Physiecology and Tillage Science in Northwestern loess Plateau, Ministry of Agriculture, Xianyang 712100 , China

基金项目:国家自然科学基金项目(41671226); 中国“十二五”国家科技支撑计划课题(2015BAD22B02); 宁夏旱作农业可持续集约化技术研究 与示范 (2019BBF03011); 陕西省博士后项目 (2017BSHEDZZ140)

收稿日期: 2019-04-13; 网络出版日期:2021-01-27

*通讯作者 Corresponding author.E-mail: jiazhk@126.com 
Abstract: Soil microbes are sensitive indicators for characterizing the quality of soil. In this study, Illumina HiSeq was used to analyze the effects of different mulching patterns on the microbial community structure and diversity of semi-humid dryland farmland soil in order to evaluate the impacts of these mulching measures on the soil quality from a microbial perspective. The soil microbial communities were tested under three different mulching patterns comprising film mulching ( $\mathrm{P})$, straw mulching $(\mathrm{S})$, and ridge and furrow mulching $(\mathrm{R})$, with conventional tillage without mulching as the control (CK). The relationships between the soil physical and chemical characteristics and microbial communities were analyzed. The results of the study indicated that each mulching treatment significantly changed the soil microbial community structure and diversity. The dominant phyla of bacterial in the soil samples among all treatments were Proteobacteria, Acidobacteria, and Actinobacteria with abundances of $29.69 \%, 28.28 \%$, and $20.76 \%$, respectively. Actinobacteria had the highest relative abundance under $\mathrm{CK}$, but a high soil $\mathrm{pH}$ and low $\mathrm{NO}_{3}-\mathrm{N}$ content inhibited the growth and reproduction of Acidobacteria in the soil. The dominant phyla of fungi were Ascomycota and Basidiomycota with abundances of 59.65\% and $20.96 \%$, respectively. The low soil temperature under the S inhibited the growth and development of Basidiomycota, and its relative abundance was the lowest among all treatments. Compared with CK, P and R significantly increased the diversity and richness of soil bacteria, while $\mathrm{S}$ and $\mathrm{R}$ significantly increased the soil fungi diversity and richness, and $\mathrm{P}$ had no significant effects on the soil fungi diversity and richness. Spearman's rank correlation coefficients showed that the soil bacterial diversity was mainly affected by the soil moisture(SM) and nitrate nitrogen contents (TN), and the soil fungi diversity was mainly affected by the soil temperature ( ST), total nitrogen, and nitrate nitrogen ( $\left.\mathrm{NO}_{3}-\mathrm{N}\right)$. Redundancy analysis showed that the microbial community structure was affected mainly by the soil moisture, soil temperature, nitrate nitrogen, and total nitrogen. In general, the diversities and abundances of soil bacteria and fungi were significantly higher under $\mathrm{R}$ than CK. The relative abundances of Basidiomycota and Glomeromycota were the highest under $\mathrm{R}$ in all treatments. The ectomycorrhiza and secondary mycorrhiza formed by these phyla can enhance the absorption of root nutrients as well as improve the stress resistance by crops. The results showed that the crop yields were the highest under R. Ridge and furrow mulching is recommended as the planting method in this semi-humid dry farming area.

Key Words : farmland mulching; microbial community; Illumina Hiseq sequencing; soil physicochemical properties

作为土壤中最活跃的部分, 微生物表现出多样的代谢功能, 直接或间接参与了大量的生物化学反应, 在陆 地生态系统中起着不可或缺的作用 ${ }^{[1-3]}$ 。研究表明, 微生物群落在调节养分循环、影响植物生产力和生态系 统稳定性方面发挥着至关重要的作用 ${ }^{[4-6]}$, 并且微生物对植被和土壤性质的改变均能迅速做出反应 ${ }^{[7-8]}$ 。因 此, 土壤微生物多样性和群落结构的变化可被作为重要和敏感的指标来表征土壤健康的短期和长期 变化 ${ }^{[3,9]}$ 。

中国北方旱地面积约占全国土地总面积的 $56 \%$ 和农业生产的 $46 \%{ }^{[10]}$, 是中国农业生产的重要地区之一。 然而, 水资源短缺、土壤肥力差是限制西北早作区农业生产的主要因素 ${ }^{[11]}$ 。因此,如何降低土壤水分蒸发, 充 分利用有限的自然降水, 提高作物对有限水分的利用效率是解决该地区作物产量的关键所在。农田覆盖通过

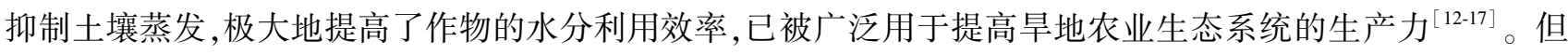
前人研究多集中于农田覆盖对土壤水分、土壤养分和作物产量的影响, 而对农田覆盖条件下土壤微生物群落 的变化了解较少。目前已有部分研究发现农田覆盖措施通过影响土壤结构、土壤微气候( 土壤水分、土壤温 度等) 和土壤养分, 可显著影响土壤微生物群落结构和多样性。陈月星等 ${ }^{[18]}$ 、董立国等 ${ }^{[19]}$ 和 Huang 等 $^{[20]}$ 研 究表明, 地表覆盖生草或秸秆均显著影响了土壤细菌群落结构及其多样性和丰富度。 Liu 等 ${ }^{[8]}$ 发现地膜覆盖

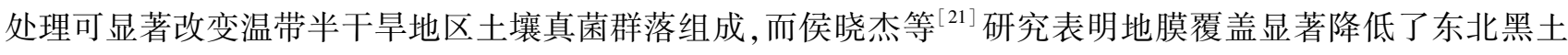
地的土壤微生物功能多样性。然而, 现有研究多集中于单一覆盖材料或模式对土壤细菌或真菌群落结构一方 面的影响,不同覆盖材料或模式间的比较鲜有报道。此外, 土壤细菌和真菌群落对农田覆盖的响应并不一致， 
因此要了解农田覆盖对土壤微生物群落结构的影响, 需同时研究不同农田覆盖模式下土壤细菌和真菌群落多 样性和组成的变化。

本研究基于 3 年连续田间试验,在西北旱作区的设置了 3 种不同覆盖方式:平作地膜覆盖 $(\mathrm{P}) 、$ 平作秸秆 覆盖 $(S)$ 和垄膜沟播覆盖 $(R)$, 以平作不覆盖为对照 $(C K)$ 。应用 Illumina HiSeq 测序技术分析土壤细菌和真 菌群落组成和多样性, 比较不同覆盖模式下的土壤微生物群落的变化, 目的是探明连年农田不同地表覆盖对 土壤微生物多样性和群落组成的影响差异, 并结合相关的土壤理化性质 (即 $\mathrm{pH}$ : 土壤酸碱度, $\mathrm{SM}$ : 土壤水分, $\mathrm{ST}$ : 土壤温度, $\mathrm{SOM}$ : 土壤有机质, $\mathrm{NO}_{3}-\mathrm{N}$ : 土壤硝态氮和 $\mathrm{TN}$ : 土壤全氮) 变化, 明确土壤微生物群落变化与土壤 理化性状之间的关系, 从而为西北旱作区农田覆盖栽培技术的合理应用提供理论依据。

\section{1 材料与方法}

\section{1 试验区概况}

本试验在陕西杨凌西北农林科技大学中国旱区节水农业研究院试验田 $\left(34^{\circ} 20^{\prime} \mathrm{N}, 108^{\circ} 04^{\prime} \mathrm{E}\right)$ 进行。该 试验区海拔 $466.7 \mathrm{~m}$, 多年平均降水量 $585.0 \mathrm{~mm}, 7$ 月至 9 月期间多年平均降雨量为 $380 \mathrm{~mm}$, 年蒸发量 993.2 $\mathrm{mm}$ 。年均气温 $13.5^{\circ} \mathrm{C}$, 年均日照时数为 $2196 \mathrm{~h}$, 无霜期 220 天。属暖温带半湿润易旱区, 土壤类型为塿土。 $0-20 \mathrm{~cm}$ 土层土壤全氮含量 $1.21 \mathrm{~g} / \mathrm{kg}$, 有机质含量 $11.97 \mathrm{~g} / \mathrm{kg}$, 全氮含量 $1.31 \mathrm{~g} / \mathrm{kg}$, 速效氮含量 $53.35 \mathrm{mg} / \mathrm{kg}$, 速效磷含量 $21.35 \mathrm{mg} / \mathrm{kg}$, 速效钾含量 $142.97 \mathrm{mg} / \mathrm{kg}$ 。容重为 $1.28 \mathrm{~g} / \mathrm{cm}^{3}$ 。耕作方式为春玉米连作。

\section{2 试验设计}

试验采用完全随机区组设计,设 3 个覆盖处理: (1) 平作地膜覆盖 $(P)$ : 覆盖方式为平膜全覆盖, 膜宽 120 $\mathrm{cm}$; (2) 平作秸秆覆盖 $(S)$ : 秸秆为玉米秸秆, 整秆均匀覆盖, 覆盖量为 $9000 \mathrm{~kg} / \mathrm{hm}^{2}$; (3) 垄膜沟播覆盖 $(\mathrm{R})$ : 沟、垄宽均为 $60 \mathrm{~cm}$, 垄高 $15 \mathrm{~cm}$, 其中垄上覆盖地膜, 膜宽 $70 \mathrm{~cm}$, 沟内种植区不进行覆膜; 以传统平作不覆盖 为对照 $(\mathrm{CK})$, 共 4 个处理, 每个处理 3 次重复, 每个小区面积 $58.8 \mathrm{~m}^{2}(14 \mathrm{~m} \times 4.2 \mathrm{~m})$ 。地膜为聚乙烯塑料地膜 (天水天宝塑业有限责任公司生产), 厚度 $0.01 \mathrm{~mm}$ 。上季作物收获后, 将各覆膜 $(\mathrm{P} 、 \mathrm{R})$ 处理的旧地膜全部移 除, 秋季整地后重新覆盖地膜。覆盖后沿地膜带垂直方向每隔 $200 \mathrm{~cm}$ 压一土带, 防大风揭膜。在 $\mathrm{S}$ 处理中, 上季作物收获后, 移除不能分解腐烂的秸秆, 秋天整地后重新覆盖秸秆。所有处理覆盖时间均为秋季作物收 获后 ( 8 月中旬) 覆盖。

试验始于 2013 年, 作物为春玉米, 品种为大丰 30 ,于每年 4 月中下旬进行播种, 8 月中旬收获。各处理播 种密度均为 67,000 株 $/ \mathrm{hm}^{2}$ (行距 $60 \mathrm{~cm}$, 株距 $25 \mathrm{~cm}$ ), 用鹰嘴播种 (施肥) 器人工播种, 播种深度为 $4-5 \mathrm{~cm}$ 。 播种时各处理用人工鹰嘴播种 (施肥) 器施用基肥 ( N $140 \mathrm{~kg} / \mathrm{hm}^{2}$ 和 $\mathrm{P}_{2} \mathrm{O}_{5} 150 \mathrm{~kg} / \mathrm{hm}^{2}$ ), 玉米播种后 65 天后在 玉米棵间进行追肥 $\left(\mathrm{N} 140 \mathrm{~kg} / \mathrm{hm}^{2}\right)$, 施肥深度为 4-5 cm, 全生育期不灌水。试验期间所有处理没有发生病 虫害,并根据情况进行人工除草。

\section{3 土壤取样}

在大田试验第 3 年的 2016 年 7 月 1 日 (播后 74 天,玉米吐丝期) 进行取样,直径 $5 \mathrm{~cm}$ 的土钻远离植物根 部以“S”形取样收集 9 个重复样品 ( $0-20 \mathrm{~cm}$ 土层的土壤), 然后混合均化作为每个重复小区的复合样品。将 样品过 $2 \mathrm{~mm}$ 篮, 移除根系和其他其他肉眼可见的杂物。每个样品分成三部分:一部分鲜土用于硝态氮 $\left(\mathrm{NO}_{3}\right.$ $\mathrm{N})$ 的测定; 一部分分装到 $50 \mathrm{~mL}$ 离心管中, 立即放人 $-80^{\circ} \mathrm{C}$ 冰箱中保存, 用于土壤微生物 DNA 的提取; 剩余土 样风干后用于土壤 $\mathrm{pH}$ 、土壤有机质 $(\mathrm{SOM})$ 、土壤全氮 $(\mathrm{TN})$ 等指标的测定。

\section{4 土壤理化性质测定}

土壤水分与温度: 取土样的同时用烘干法测定 0-20 cm 土壤水分 (SM), 每个小区 3 次重复。同时用地 温计在取样前后连续 3 天测定 5、10、15、20 cm 的土壤温度 (ST), 以 5-20 厘米的土壤温度的平均值作为每个 小区的土壤温度。

土壤 $\mathrm{pH}$ : 取风干土 $10 \mathrm{~g}$, 按土:水 $=1: 2.5$ 的倍数加人 $25 \mathrm{~mL}$ 水后剧烈震荡摇勺后, 静置 $30 \mathrm{~min}$, 用 $\mathrm{pH}$ 计测定 ${ }^{[2]}$ 。 
土壤养分测定: 土壤有机质采用重铬酸钾氧化法测定 ${ }^{[22]}$; 土壤全氮含量采用凯氏定氮法测定 ${ }^{[22]}$; 土壤硝 态氮含量采用流动分析仪进行测定: 取新鲜土样 $5 \mathrm{~g}$, 加人 $50 \mathrm{~mL} 1.0 \mathrm{~mol} / \mathrm{L} \mathrm{KCl}$ 振荡 $30 \mathrm{~min}$, 然后过滤提取物, 使用流动分析仪 (Autoanalyzer 3, Bran Luebbe, 德国) 测定硝态氮浓度。

1.5 DNA 提取和 Illumina HiSeq 测序

土壤微生物 DNA 使用 FastDNA 试剂盒 (MP Biomedicals, USA) 提取。应用带有 barcode 的特异引物序列 ( 细菌: 341F 5'-CCTACGGGRSGCAGCAG- $3^{\prime}$ 和 806R 5'-GGACTACVVGGGTATCTAATC- $3^{\prime}$; 真菌: F2045 5'GCATCGATGAAGAACGCAGC- $3^{\prime}$ 和 R2390 5'-TCCTCCGCTTAT TGATATGC- $3^{\prime}$ ) 扩增相应土壤细菌 16S rRNA V3-V4 区域和真菌 ITS 基因。扩增体系包括:2×KAPA HiFi Hotstart ReadyMix $15 \mu \mathrm{L}$,正反向引物各 $1 \mu \mathrm{L}, 10 \mathrm{ng}$ DNA 模板,最后用 $\mathrm{dd} \mathrm{H}_{2} \mathrm{O}$ 补足至 $30 \mu \mathrm{L}$ 。 PCR 扩增条件为: $95^{\circ} \mathrm{C}$ 预变性 $3 \mathrm{~min}$; 然后 $94^{\circ} \mathrm{C}$ 变性 $20 \mathrm{~s}, 58^{\circ} \mathrm{C}$ 退火 $30 \mathrm{~s}, 72^{\circ} \mathrm{C}$ 延伸 $30 \mathrm{~s}$ 持续 24 个循环; 最后 $72^{\circ} \mathrm{C}$ 延伸 $150 \mathrm{~s}$ 结束。

扩增子使用 AxyPrep DNA 凝胶提取试剂盒 (Axygen Biosciences, Union City, CA, USA) 从 2\%琼脂糖凝胶中 提取并使用 Qubit dsDNA HS Assay Kit(Promega,USA) 纯化 DNA。将纯化的扩增子以等摩尔浓度合并,然后 根据标准方案在 Illumina HiSeq PE250 平台上进行配对末端测序 $(2 \times 250$ bp $)$ 。Illumina HiSeq 测序在上海锐

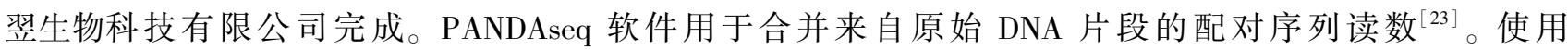
USEARCH v5.2.32 对序列进行进一步分析, 通过聚类相似序列的差异小于 $3 \%$ 来过滤和去噪数据。对微生物 生态学管道软件的定量分析被用来通过将聚类 OTUs 的读数组合为 $97 \%$ 相似性来选择操作分类单元 ( Operational Taxonomic Units, OTU) ${ }^{[24]}$ 。

\section{6 数据分析}

采用单因素方差分析法分析土壤理化性状, 以确定处理之间的差异 (显著差异在 $95 \%$ 的置信水平下确 定)。当检测到显著性时 $(P<0.05$ 水平), 使用邓肯法进行多重比较。使用 QIIME 软件计算阿尔法多样性。 用 Chao1 估计法和 Shannon 多样性指数计算细菌群落估计的丰富度和多样性。使用 Canoco 5.0 软件进行冗 余分析 (Redundancy analysis, RDA), 以辨别微生物群落组成与环境参数之间的相关性。在 RDA 中选择 manual forward selection 程序以使用具有 999 个排列的蒙特卡罗测试来确定环境变量参数的显著性。 Spearman 的等级相关性用于测试微生物群落组成与土壤理化性质之间的关联。使用 SPSS18.0 ( SPSS Inc., Chicago,IL, USA) 进行所有统计分析和 Spearman 等级相关性分析。

\section{2 结果与分析}

\section{1 土壤理化性质}

连续覆盖 3 年后, 各处理的土壤理化性质发生了显著变化 (表 1 )。覆盖处理 $(\mathrm{P} 、 \mathrm{~S}$ 和 $\mathrm{R}$ ) 显著降低了土壤 $\mathrm{pH}(P=0.01)$; 与 $\mathrm{CK}$ 相比, $\mathrm{R}$ 和 $\mathrm{S}$ 处理 $\mathrm{TN}$ 和 $\mathrm{NO}_{3}-\mathrm{N}$ 含量 $(P<0.01)$ 分别显著提高 $12.84 \% 、 7.96 \%$ 和 $14.95 \%$ 、 $25.13 \%$,而 $\mathrm{P}$ 处理下玉米营养生长旺盛,过度消耗地力, 土壤 TN 含量较 CK 显著降低 $5.08 \%$; 覆盖模式对 SOM 影响不显著, 各处理下土壤 SOM 含量在 $15.00-15.58 \mathrm{mg} / \mathrm{kg} ; \mathrm{P}$ 和 R 处理均显著提高了 SM 和 ST, 春玉 米产量较 CK 分别显著提高 $17.4 \%$ 和 $16.69 \%$ (图 1)。秸秆覆盖对 SM、ST 和产量影响不显著。

2.2 土壤微生物群落多样性及与土壤理化特性的关系

采用操作分类单元 (OTU) 水平方法计算不同覆盖条件下微生物群落丰富度和多样性 (表 2) 可知, 各覆 盖处理 $(\mathrm{P}, \mathrm{S}$ 和 R) 下土壤细菌的 OTU、Chao1 指数和 Shannon 多样性指数较 CK 处理均有提高。而真菌丰富 度和多样性对覆盖模式的响应不同, 除 $\mathrm{P}$ 处理外, 其他覆盖处理 $(\mathrm{S}$ 和 R) 的 Chao1 指数、OTU 和 Shannon 多样 性指数均显著高于 CK, 而 $\mathrm{P}$ 处理下土壤真菌多样性和丰富度与 CK 处理相比差异不显著。Spearman 相关系 数分析表明, 细菌群落的 OTU 和 Shannon 多样性指数与 SM 均呈显著正相关, OTU 和 Chao 1 指数与 $\mathrm{NO}_{3}-\mathrm{N}$ 含 量呈极显著正相关; 真菌群落的 OTU、Chao1 指数和 Shannon 指数均与 ST 呈显著负相关, 和 $\mathrm{TN} 、 \mathrm{NO}_{3}-\mathrm{N}$ 含量均 呈显著正相关(图 2)。 
表 10 - $20 \mathrm{~cm}$ 土层土壤理化性质

Table 1 Soil physicochemical properties measured in the $0-20 \mathrm{~cm}$ soil layer

\begin{tabular}{ccccccc}
\hline $\begin{array}{c}\text { 处理 } \\
\text { Treatments }\end{array}$ & $\mathrm{pH}$ & $\begin{array}{c}\mathrm{TN} / \\
(\mathrm{g} / \mathrm{kg})\end{array}$ & $\begin{array}{c}\mathrm{SOM} / \\
(\mathrm{g} / \mathrm{kg})\end{array}$ & $\begin{array}{c}\mathrm{NO}_{3}-\mathrm{N} / \\
(\mathrm{mg} / \mathrm{kg})\end{array}$ & $\mathrm{SM} / \%$ & $\mathrm{ST} /{ }^{\circ} \mathrm{C}$ \\
\hline $\mathrm{P}$ & $7.37 \pm 0.26 \mathrm{~b}$ & $0.82 \pm 0.08 \mathrm{~d}$ & $15.44 \pm 1.33 \mathrm{a}$ & $12.60 \pm 0.79 \mathrm{bc}$ & $14.55 \pm 0.74 \mathrm{a}$ & $28.73 \pm 0.84 \mathrm{a}$ \\
$\mathrm{S}$ & $7.36 \pm 0.14 \mathrm{~b}$ & $0.93 \pm 0.04 \mathrm{~b}$ & $15.58 \pm 1.24 \mathrm{a}$ & $13.75 \pm 0.53 \mathrm{ab}$ & $12.92 \pm 0.68 \mathrm{c}$ & $25.86 \pm 1.06 \mathrm{~b}$ \\
$\mathrm{R}$ & $7.29 \pm 0.33 \mathrm{~b}$ & $0.97 \pm 0.07 \mathrm{a}$ & $15.43 \pm 1.45 \mathrm{a}$ & $14.96 \pm 0.66 \mathrm{a}$ & $13.75 \pm 0.67 \mathrm{~b}$ & $27.57 \pm 0.97 \mathrm{ab}$ \\
$\mathrm{CK}$ & $7.53 \pm 0.22 \mathrm{a}$ & $0.86 \pm 0.10 \mathrm{c}$ & $15.00 \pm 1.64 \mathrm{a}$ & $11.96 \pm 0.94 \mathrm{c}$ & $12.47 \pm 0.58 \mathrm{c}$ & $26.89 \pm 0.84 \mathrm{~b}$ \\
& $P=0.01$ & $P<0.01$ & $\mathrm{~ns}$ & $P=0.012$ & $P<0.01$ & $P=0.01$ \\
\hline
\end{tabular}

$P:$ 平作地膜覆盖 Plastic film mulching; $S:$ 平作秸秆覆盖 Straw mulching; R : 垄膜沟播覆盖 Ridges and furrows with only the ridges mulched with plastic film; CK: 裸地平作 conventional tillage without mulching. $\mathrm{pH}$ : 土壤酸碱度 soil acidity; $\mathrm{TN}$ : 全氮 total nitrogen; SOM: 有机质 Soil organic matter; $\mathrm{NO}_{3}-\mathrm{N}$ : 硝态氮 Soil nitrate nitrogen; SM: 土壤含水量 soil water content; $\mathrm{ST}$ : 土壤温度(在该表中使用土壤 $5 \mathrm{~cm}, 10 \mathrm{~cm}, 15 \mathrm{~cm}$ 和 $20 \mathrm{~cm}$ 处 温度的平均值) soil temperatures (the average values of $5 \mathrm{~cm}, 10 \mathrm{~cm}, 15 \mathrm{~cm}$, and $20 \mathrm{~cm}$ soil layers were used in this table) 结果表示为平均值沶准误, 同列数据后不同字母表示差异达到 $5 \%$ 的显著水平

2.3 土壤微生物群落结构及与土壤理化特性的关系 通过对所有土壤样品进行质量测序,细菌群落和真 菌群落分别获得 143025 和 139826 个序列。每个样本 的细菌序列数量为 $33155-38411$ (平均值 $=35756$ ), 而 真菌序列的数量为 $33438-36800$ (平均值 $=34957$ )。 由图 3 可知，细菌的优势门是变形菌门 (Proteobacteria)、酸杆菌门(Acidobacteria) 和放线菌门 (Actinobacteria)，它们的相对丰度范围分别为 $28.92 \%-$ $30.55 \% 、 25.66 \%-30.48 \%$ 和 $17.85 \%-27.3 \%$ 。真菌群 落的优势门是子囊菌门 (Ascomycota)、担子菌门 (Basidiomycota)、球囊菌门(Glomeromycota) 和接合菌门 (Zygomycota)，它们的相对丰度范围分别为 $49.78 \%$ $64.36 \%, 13.52 \%-33.44 \%, 5.55 \%-7.75 \%$ 和 $3.93 \%-$ $10.27 \%$ 。另外, 在所有样品中均发现了低丰度的壶菌 门(Chytridiomycota)。

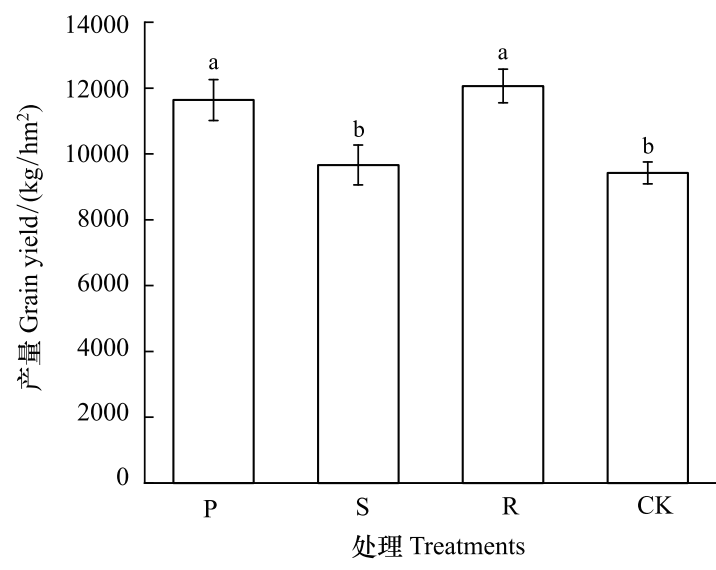

图 1 不同覆盖处理的玉米产量

Fig.1 Corn yield under different mulching treatments P : 平作地膜覆盖 Plastic film mulching; S: 平作秸秆覆盖 Straw mulching; R : 垄膜沟播覆盖 Ridges and furrows with only the ridges mulched with plastic film; CK: 裸地平作 conventional tillage without mulching

表 2 不同覆盖处理土壤微生物的丰富度和多样性指数

Table 2 Richness and diversity index of soil microbial communities under the different mulching treatments

\begin{tabular}{|c|c|c|c|c|c|c|}
\hline \multirow{2}{*}{$\begin{array}{c}\text { 处理 } \\
\text { Treatments }\end{array}$} & \multicolumn{3}{|c|}{ 细菌 Bacteria } & \multicolumn{3}{|c|}{ 真菌 Fungi } \\
\hline & OTU & Chao1 & Shannon & OTU & Chao1 & Shannon \\
\hline $\mathrm{P}$ & $2467 \pm 53.91 \mathrm{a}$ & $3240 \pm 64.82 \mathrm{a}$ & $9.72 \pm 0.11 \mathrm{a}$ & $427 \pm 14.15 b$ & $463 \pm 13.64 b$ & $6.42 \pm 0.27 \mathrm{~b}$ \\
\hline $\mathrm{S}$ & $2473 \pm 37.70 \mathrm{a}$ & $3300 \pm 63.74 a$ & $9.55 \pm 0.89 \mathrm{ab}$ & $589 \pm 27.77 \mathrm{a}$ & $634 \pm 23.9 \mathrm{a}$ & $7.17 \pm 0.28 \mathrm{a}$ \\
\hline $\mathrm{R}$ & $2521 \pm 47.58 \mathrm{a}$ & $3322 \pm 68.61 \mathrm{a}$ & $9.73 \pm 0.10 \mathrm{a}$ & $550 \pm 23.23 \mathrm{a}$ & $615 \pm 28.78 \mathrm{a}$ & $7.05 \pm 0.29 a$ \\
\hline \multirow[t]{2}{*}{ CK } & $2276 \pm 53.92 b$ & $3033 \pm 104.07 \mathrm{~b}$ & $9.45 \pm 0.08 \mathrm{~b}$ & $476 \pm 18.23 b$ & $514 \pm 17.09 \mathrm{~b}$ & $6.14 \pm 0.25 b$ \\
\hline & $P=0.005$ & $P=0.021$ & $P=0.035$ & $P<0.01$ & $P<0.01$ & $P=0.015$ \\
\hline
\end{tabular}

OTU: 操作分类单元 Operational Taxonomic Units; Chao1:Chao1 指数 Chao1 index; Shannon: Shannon 多样性指数 Shannon diversity index

此外,Spearman 等级相关分析 (表 3) 表明土壤理化特性显著影响了微生物群落组成。在细菌群落组成 中,酸杆菌门的相对丰度与 $\mathrm{TN} 、 \mathrm{NO}_{3}-\mathrm{N}$ 和 $\mathrm{SOM}$ 呈显著正相关, 与 $\mathrm{pH}$ 呈显著负相关。芽单胞菌门 (Gemmatimonadetes) 和拟杆菌 (Bacteroidetes) 的相对丰度均与 TN 呈显著正相关。此外, $\mathrm{NO}_{3}-\mathrm{N}$ 也和拟杆菌呈 

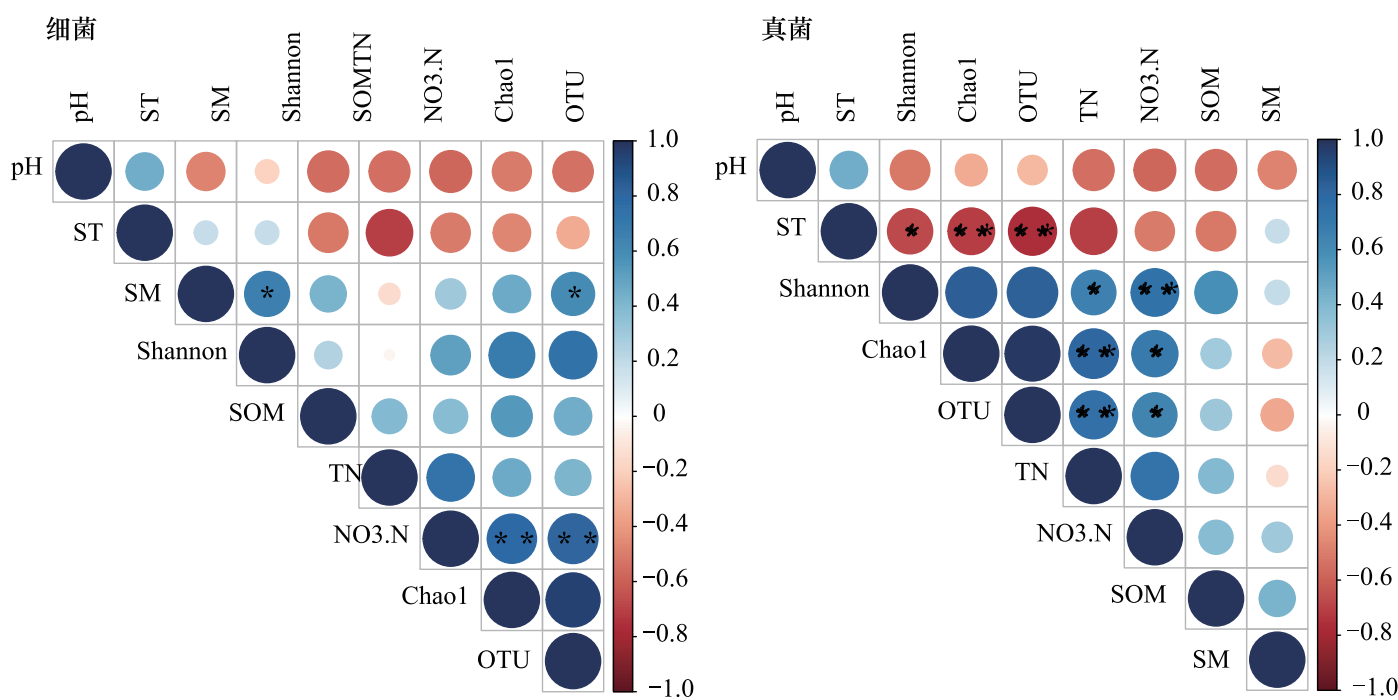

图 2 土壤微生物多样性与环境因子的斯皮尔曼相关系数

Fig.2 Spearman correlation coefficient between soil microbial diversity and environmental factors

$*: P<0.05 ; * *: P<0.01 ; \mathrm{SM}$ : 土壤含水量 soil water content; $\mathrm{ST}$ : 土壤温度(在该表中使用土壤 $5 \mathrm{~cm}, 10 \mathrm{~cm}, 15 \mathrm{~cm}$ 和 $20 \mathrm{~cm}$ 处温度的平均 值) soil temperatures( the average values of $5 \mathrm{~cm}, 10 \mathrm{~cm}, 15 \mathrm{~cm}$, and $20 \mathrm{~cm}$ soil layers were used in this table)结果表示为平均值土标准误; OTU: 操作分类单元 Operational Taxonomic Units; Chaol: Chao1 指数 Chao1 index; Shannon: Shannon 多样性指数 Shannon diversity index
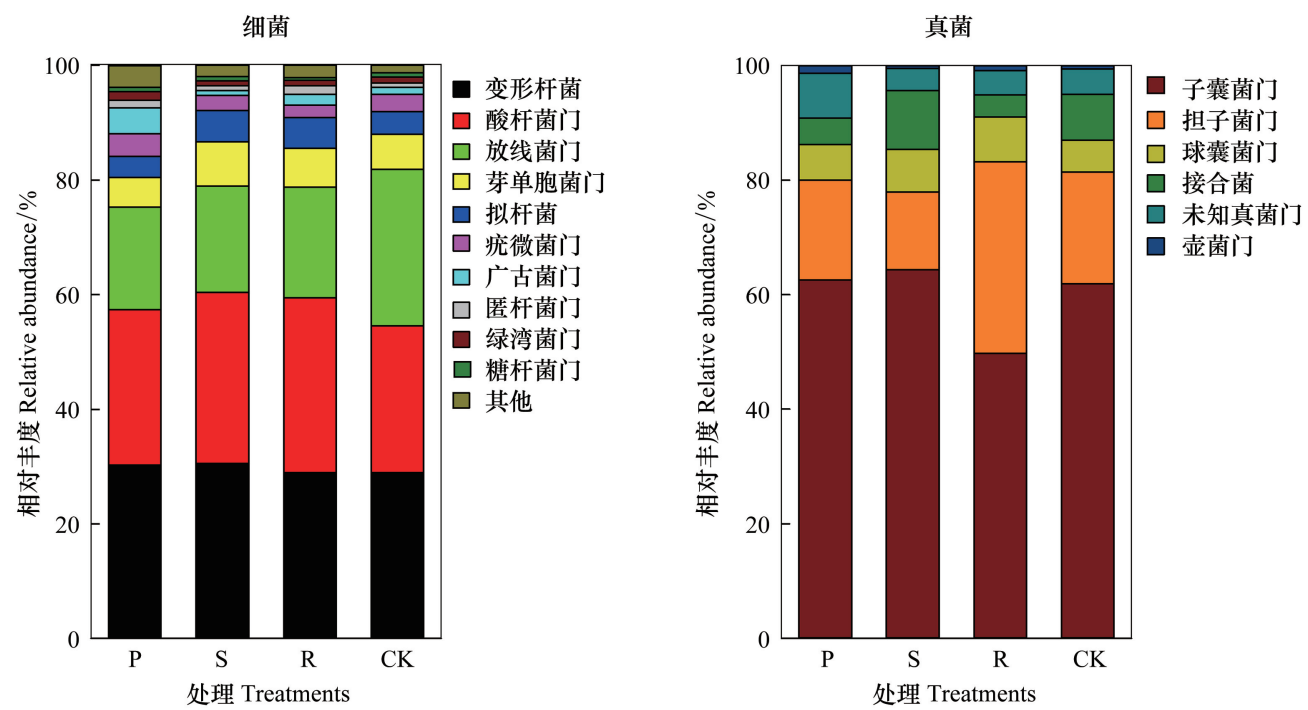

图 3 不同处理土壤微生物群落在门分类水平下的组成和相对丰度

Fig.3 Composition and relative abundance of different soil microbial communities at the phyla classification level

显著正相关。对于真菌群落而言,ST 显著影响担子菌门和接合菌门,并与前者呈显著正相关,后者与之相反。 球囊菌门与 $\mathrm{TN}$ 和 $\mathrm{NO}_{3}-\mathrm{N}$ 呈显著正相关, 与 $\mathrm{pH}$ 则呈显著负相关。呈菌门的相对丰度与 $\mathrm{SM}$ 呈显著正相关。 由此可知土壤温度和氮含量是改变微生物群落组成的主要因素。

采用冗余分析 (RDA) 进一步分析各土壤环境因子与微生物群落结构之间的关系。图 4 为细菌群落结构 与土壤理化性质之间的关系, 蒙特卡洛置换检验表明 (表 4), 土壤 $\operatorname{SM}(F=10.1, P=0.001) 、 \mathrm{ST}(F=4.5, P=$ $0.012)$ 和 $\mathrm{TN}(F=3.7, P=0.025)$ 是细菌群落变异的三个最重要的贡献者。所有的环境变量共同解释了样本 间细菌群落变异的 $86.7 \%$, 影响大小顺序为 $\mathrm{SM}>\mathrm{ST}>\mathrm{TN}>\mathrm{NO}_{3}-\mathrm{N}>\mathrm{pH}>\mathrm{SOM}$ 。 $\mathrm{RDA}$ 的前两个排序轴分别解释了 
总方差的 $59.96 \%$ 和 $16.63 \%$ 。在第一个排序轴上, 来自 P 处理样品点的聚集度与其余处理的样品点的聚集度 相距较远。图 4 为真菌群落结构与土壤理化性质之间的关系, 影响真菌群落组成最大的土壤理化性质为 SM $(F=6.2, P=0.004)$ (表 4)。所有的环境变量共同解释了样本间真菌群落变异的 $83.4 \%$, 影响的顺序为 SM> $\mathrm{TN}>\mathrm{ST}>\mathrm{NO}_{3}-\mathrm{N}>\mathrm{pH}>\mathrm{SOM}_{\circ}$ RDA 的前两个排序轴分别解释了总方差的 $51.9 \%$ 和 $26.6 \%$, 在第一个排序轴上, $\mathrm{CK}$ 和 $\mathrm{S}$ 处理的样品点距离较近, 来自 $\mathrm{P}$ 和 $\mathrm{R}$ 处理样品点的聚集度与它们相距较远。

表 3 土壤微生物 (门分类水平) 的群落组成与土壤理化性质的 Spearman 等级相关系数

Table 3 Correlation coefficients between soil microbial community composition (phyla) and soil physicochemical properties

\begin{tabular}{|c|c|c|c|c|c|c|c|}
\hline & 门水平 Phyla & $\mathrm{pH}$ & $\mathrm{TN}$ & SOM & $\mathrm{NO}_{3}-\mathrm{N}$ & SM & ST \\
\hline \multirow[t]{10}{*}{ 细菌 Bacteria } & 变形杆菌 & 0.039 & -0.035 & 0.445 & 0.14 & 0.315 & 0.035 \\
\hline & 酸杆菌门 & $-0.595^{*}$ & $0.587^{*}$ & $0.588^{*}$ & $0.846^{* *}$ & 0.448 & 0.217 \\
\hline & 放线菌门 & 0.539 & 0.021 & -0.462 & -0.119 & -0.497 & -0.042 \\
\hline & 芽单胞菌门 & -0.126 & $0.601^{*}$ & 0.305 & 0.573 & -0.357 & -0.469 \\
\hline & 拟杆菌 & -0.27 & $0.762^{* *}$ & 0.326 & $0.804^{* *}$ & -0.126 & -0.217 \\
\hline & 疮微菌门 & 0.525 & $-0.790^{* *}$ & -0.039 & $-0.608^{*}$ & 0.189 & -0.007 \\
\hline & 广古菌门 & -0.123 & -0.42 & 0.018 & -0.049 & $0.804^{* *}$ & $0.853^{* *}$ \\
\hline & 匿杆菌门 & -0.427 & 0.105 & 0.147 & 0.531 & $0.755^{* *}$ & $0.748^{* *}$ \\
\hline & 绿弯菌门 & 0.371 & -0.392 & -0.13 & -0.294 & 0.217 & 0.483 \\
\hline & 糖杆菌门 & $0.578 *$ & -0.35 & -0.067 & -0.196 & -0.217 & -0.336 \\
\hline \multirow[t]{6}{*}{ 真菌 Fungi } & 子囊菌门 & 0.441 & -0.524 & 0.095 & -0.336 & -0.021 & -0.343 \\
\hline & 担子菌门 & -0.182 & 0.336 & -0.228 & 0.35 & 0.161 & $0.678^{*}$ \\
\hline & 球囊菌门 & $-0.676^{*}$ & $0.734^{* *}$ & 0.571 & $0.860 * *$ & 0.294 & 0.105 \\
\hline & 接合菌 & 0.501 & -0.133 & 0.025 & -0.252 & -0.545 & $-0.783^{* *}$ \\
\hline & 未知真菌门 & 0.207 & $-0.636^{*}$ & -0.102 & -0.343 & $0.594^{*}$ & 0.552 \\
\hline & 壸菌门 & -0.228 & -0.336 & 0.042 & -0.014 & $0.825^{* *}$ & $0.888^{* *}$ \\
\hline
\end{tabular}
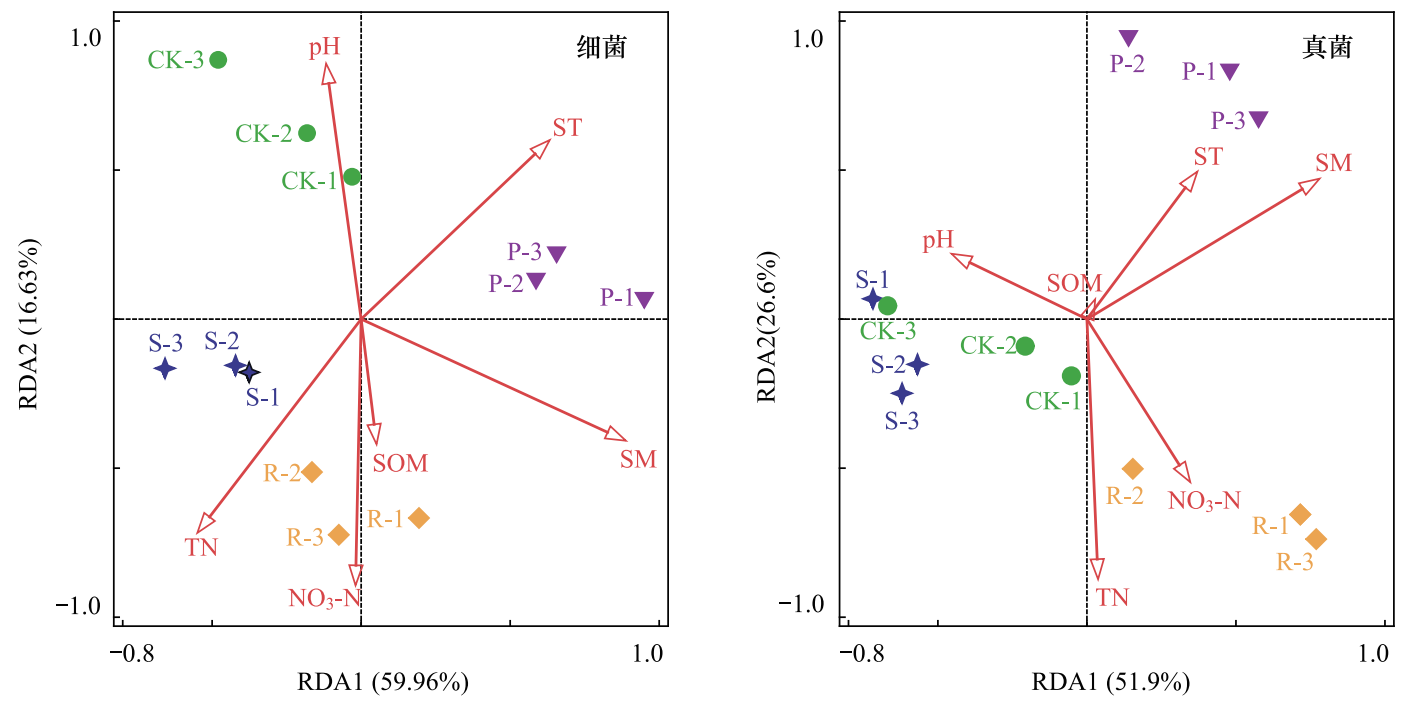

图 4 土壤微生物群落结构与土壤理化特性的圥余分析( RDA)

Fig.4 Redundancy analysis (RDA) of soil microbial community structure and soil physicochemical properties 
表 4 环境变量对土壤微生物群落分布的贡献及其显著性

Table 4 The contributions and significances of environmental variables to soil microbial community compositions

\begin{tabular}{|c|c|c|c|c|c|c|}
\hline \multirow{2}{*}{$\begin{array}{c}\text { 土壤理化因子 } \\
\text { Soil properties factors }\end{array}$} & \multicolumn{3}{|c|}{ 细菌 Bacteria } & \multicolumn{3}{|c|}{ 真菌 Fungi } \\
\hline & 贡献率/\% & $F$ & $P$ & 贡献率 $/ \%$ & $F$ & $P$ \\
\hline SM & 50.3 & 10.1 & 0.001 & 38.1 & 6.2 & 0.004 \\
\hline ST & 30.8 & 4.5 & 0.012 & 15.7 & 1.9 & 0.173 \\
\hline $\mathrm{TN}$ & 26.9 & 3.7 & 0.025 & 20.9 & 2.6 & 0.082 \\
\hline $\mathrm{NO}_{3}-\mathrm{N}$ & 14.4 & 1.7 & 0.187 & 15.6 & 1.9 & 0.157 \\
\hline $\mathrm{pH}$ & 14.0 & 1.6 & 0.203 & 14.2 & 1.7 & 0.201 \\
\hline SOM & 4.7 & 0.5 & 0.688 & 1.9 & 0.2 & 0.893 \\
\hline
\end{tabular}

\section{3 讨论}

\section{1 覆盖对土壤微生物多样性的影响}

土壤微生物可以敏感地指示气候和土壤环境条件的变化 ${ }^{[3,9]}$, 同时土壤微生物多样性受土壤养分、结构、 $\mathrm{pH}$ 、温度和水分等条件的影响 ${ }^{[2]}$ 。前人研究发现, 秸秆覆盖、麦草覆盖以及集雨地膜覆盖均有利于维持土壤 微生物多样性, 提高土壤微生物群落的丰富度和群落物种的均匀度 ${ }^{[18,25-26]}$ 。本研究发现各覆盖处理 (秥秆覆 盖: $S$ 、垄膜沟播覆盖: $R$ 、地膜覆盖: $P$ ) 均显著提高了土壤细菌多样性和丰富度, 而不同覆盖措施对土壤真菌多 样性影响不同 (表 2), 这主要与土壤理化性质的变化有关。我们发现土壤细菌多样性主要受土壤水分的影响 (图 2), 水分通过改变微生物的细胞渗透状态、土壤基质有效性、 $\mathrm{pH}$ 值、气体扩散和温度等直接或间接影响土 壤微生物的多样性, 微生物尤其是细菌在相对较高的水势环境下活性更高 ${ }^{[27-28]}$ 。而本试验中的各覆盖处理 $(\mathrm{P} 、 \mathrm{~S}$ 和 $\mathrm{R}$ ) 均能有效改善半干旱区的土壤水分条件 (表 1), 为土壤细菌的生长提供了一个稳定而潮湿的环境 促进其生长和繁殖。覆盖措施对微生物丰富度的积极影响可能还要得益于某些优势菌门的丰度增加, 如酸杆 菌门(Acidobacteria) 和球囊菌(Glomeromycota)（图 3)，这表明覆盖措施促进了微生物在选择性方向上发育。 此外本试验还发现, 与细菌相比, 秸秆覆盖和垄膜沟播种植方式会导致微生物群落 $\alpha$ 多样性中更高的真菌优 势 (表 2)。这是因为土壤真菌比细菌具有更广的适应性和多功能性 ${ }^{[29]}$, 由于真菌擅长分解有机物, 垄沟结构 促进了作物根系的生长从而分泌更多的有机物 ${ }^{[26]}$, 秸秆覆盖植物残渣持续的碳氮输人, 这些都优先刺激了真 菌的生长和增殖, 真菌丰富度的增加又使其分解有机物能力更强, 由此形成良性循环, 这有利于农业系统中土 壤 SOM 稳定和土壤健康 ${ }^{[30]}$ 。对于土壤真菌群落多样性和丰富度而言土壤温度是主要影响因素, 且二者之间

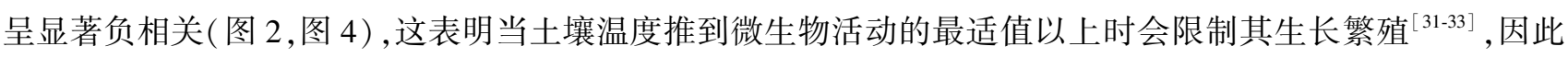
地膜覆盖 $(\mathrm{P})$ 处理下较高的土壤温度在一定程度上限制了土壤真菌的生长 ${ }^{[34]}$ 。相比之下, 仅用塑料薄膜覆 盖垄部的 $\mathrm{R}$ 处理下的土壤部分热量会从沟中裸露部分逸散出来, 为土壤真菌群落的生长提供了更适宜土壤 温度。而秸秆覆盖 $(S)$ 对土壤真菌群落多样性和丰富度的积极作用还要归因于玉米秸秆腐解后有机物可以 归还土壤并以此补充土壤有机碳氮养分, 为土壤真菌提供了丰富的碳源和氮源 ${ }^{[35-36]}$ 。此外, 土壤养分也是影 响土壤微生物 (细菌和真菌) 多样性的另一主要因素, 由于本试验所处地区降水时空分布不均, 土壤缺水时植 物会受到胁迫而改变其对地下的碳分配, 影响作物与微生物之间的竞争策略, 进而改变土壤微生物多样 性 ${ }^{[37-38]}$ 。相关性分析表明土壤微生物多样性与土壤养分 $\left(\mathrm{TN}\right.$ 和 $\left.\mathrm{NO}_{3}-\mathrm{N}\right)$ 呈显著正相关, 垄膜沟播 $(\mathrm{R})$ 处理的 垄沟结构促进了作物根系的生长从而分泌更多的有机物 ${ }^{[13,26]}$, 以及秸秆覆盖下调落物持续的碳氮输人均为 土壤微生物群落生长创造了良好的土壤养分环境。 $\mathrm{P}$ 覆盖处理下较高的土壤水分和土壤温度促使作物旺长, 消耗了大量的土壤养分, 使土壤微生物和作物竞争有限的矿化养分 ${ }^{[39]}$, 不利于土壤微生物群落的发展。因 此, $\mathrm{S}$ 和 $\mathrm{R}$ 处理土壤均同时提高了土壤细菌和真菌群落多样性和丰富度, 而 $\mathrm{P}$ 处理下土壤真菌群落多样性和 丰富度与对照处理无显著性差异。这些都是农田覆盖引起的土壤微环境的改变, 最终导致的土壤微生物多样 性的差异 ${ }^{[40]}$ 。 


\section{2 覆盖对土壤微生物群落结构的影响}

本研究发现农田覆盖措施显著影响了土壤微生物群落的组成, 所有样品中土壤细菌群落中的优势种群为 变形菌门(Proteobacteria)、酸杆菌门(Acidobacteria) 和放线菌门(Actinobacteria)。同样, 金志薇等 ${ }^{[41]}$ 、Lipson 等 ${ }^{[42]}$ 和陈月星等 ${ }^{[17]}$ 研究发现放线菌门和变形菌门也是高寒草地、高山和果园土壤环境中最常见的类群。此 外我们发现各覆盖处理 (P、S 和 R)下变形菌门和酸杆菌门的相对丰度均高于对照 (图 3), 这是由于变形菌作 为一种嗜营养菌, 富碳环境可刺激其快速增长 ${ }^{[43]}$, 因此农田覆盖条件下土壤中丰富的 $\mathrm{SOM}$ 和 $\mathrm{NO}_{3}-\mathrm{N}$ 为变形 菌提供了充足的代谢底物促进了其生长和繁殖;酸杆菌被认为可分解难降解的碳源, 对于分解植物残渣来分 泌 $\beta$-葡萄糖苷酶和木聚糖酶起着重要作用 ${ }^{[44]}$, 各覆盖处理下较低的 $\mathrm{pH}$ 和丰富的碳氮养分刺激了酸杆菌的 生长, 进而会加速土壤中现有碳源的分解 ${ }^{[44-46]}$ 。放线菌已被发现广泛分布在陆地生态系统中, 特别是在干旱 土壤中。各覆盖处理 $(P 、 S$ 和 $R)$ 的放线菌相对丰度均低于 $\mathrm{CK}$, 这可能是由于地表覆盖抑制了土壤水分蒸发, 增强了储水能力,因此放线菌门的相对丰度在土壤含水量较低的 CK 中最高。

本研究中真菌群落以子囊菌门 (Ascomycota) 和担子菌门 (Basidiomycota) 为主,二者作为腐生菌是复杂化 合物的重要分解者, 对分解植物残体和降解秸秆残留物具有重要作用 ${ }^{[47-48]}$ 。其中 $\mathrm{R}$ 处理下子囊菌门相对丰 度较低, 与 $\mathrm{NO}_{3}-\mathrm{N}$ 含量呈负相关, 这与李瑞霞等 ${ }^{\left[{ }^{[49}\right]}$ 研究结果一致。此类别中的大多数物种在土壤生态系统中 反硝化作用中起重要作用,影响土壤碳的分解, $\mathrm{R}$ 处理中较低的子囊菌门相对丰度反而会反硝化过程中产生 较少的温室气体 $\mathrm{N}_{2} \mathrm{O}$, 可能有利于生态圈平衡 ${ }^{[45]}$ 。与之相反, 担子菌门 (Basidiomycota) 相对丰度在 $\mathrm{R}$ 处理土 壤中比较丰富,远高于其他处理,表明垄膜沟播覆盖为担子菌的生存提供了良好的栖息环境。有研究表明担 子菌可以与植物形成外生菌根, 加速了作物根系对水分和养分的吸收 ${ }^{[46]}$, 有益于作物产量的形成。我们的试 验结果也显示 $\mathrm{R}$ 处理产量为所有处理最高 (图 1)。球囊菌 (Glomeromycota) 可构成陆生植物的丛枝菌根, 形 成菌根的球囊菌广泛的分布在全世界的土壤中, 它和植物的根形成共生关系, 促进根部养分吸收和生长, 对提 高植物抗旱性、耐涝性、耐盐性以及植物对害虫和病原体的抵抗力发挥着重要作用 ${ }^{[50-52]}$ 。本研究发现各覆盖 处理 $(P 、 S 、 R)$ 下土壤中球囊菌门的相对丰度均大于 $\mathrm{CK}$, 这是由于土壤中较低的 $\mathrm{pH}$ 和丰富氮含量有利于球 囊菌的生长 ${ }^{[53]}$ 。因此, 本研究认为, 覆盖模式通过改善土壤水温和氮含量, 改变了微生物的群落结构, 微生物 群落反过来调节作物对土壤水分和养分的吸收利用,促进了作物的生长发育,最终各覆盖处理玉米产量较 CK 均有不同程度提高。 $\mathrm{P}$ 处理虽然显著提高了玉米产量,但是由于该处理作物对土壤养分的过度消耗, 导致土 壤氮含量较低 (表 1), 不利于土壤的可持续利用。 $\mathrm{R}$ 和 $\mathrm{S}$ 处理均提高了微生物多样性,有利于维持长期的土 壤健康。而 $\mathrm{S}$ 处理虽然改善了作物根区的土壤水分条件,但是秸秆覆盖下较低的土壤温度抑制了微生物对养 分的转化和供给, 限制了种子的萌发、根茎叶的形成乃至生殖生长的进程, 导致土壤营养状况虽然良好而作物 产量和 CK 差异并不显著。 $\mathrm{R}$ 处理下适宜的土壤水分和温度为微生物提供了良好的生存环境, 有利于土壤养 分的释放,作物产量显著提高。

\section{4 结论}

农田覆盖显著改变了土壤理化性质 $\left(\mathrm{pH}, \mathrm{TN}, \mathrm{NO}_{3}-\mathrm{N}, \mathrm{SM}\right.$ 和 $\mathrm{ST}$ ), 且与土壤微生物群落密切相关, 分别解 释了细菌群落 $86.7 \%$ 和真菌群落 $83.4 \%$ 的变化。土壤水分是对微生物多样性影响贡献率最大的理化因子, 地 表覆盖通过提高土壤水分含量增加了土壤微生物多样性。微生物群落组成变化主要受 $\mathrm{SM} 、 \mathrm{ST} \mathrm{NO}_{3}-\mathrm{N}$ 及 $\mathrm{TN}$ 含量的影响, 地表覆盖下较高的 $\mathrm{NO}_{3}-\mathrm{N}$ 含量提高了土壤中酸杆菌门(Acidobacteria) 和球囊菌 (Glomeromycota) 的相对丰度; 秸秆覆盖降低了 ST, 抑制了担子菌门 (Basidiomycota) 的生长繁殖。与其他覆盖处理相比, 垄膜 沟播处理 $(\mathrm{R})$ 提高了土壤细菌和真菌的丰富度与多样性, 增加了部分有利于作物生产菌门(酸杆菌门、球囊 菌、担子菌门) 的相对丰度,春玉米产量为所有处理中最高。因此,建议采用垄膜沟播 $(\mathrm{R})$ 作为该地区的种植 方式。 


\section{参考文献 (References) :}

[1] 尹国丽, 李亚娟, 张振粉, 李小龙, 张晓燕, 师尚礼. 不同草田轮作模式土壤养分及细菌群落组成特征. 生态学报, 2020，40(5)： $1542-1550$

[ 2 ] van der Heijden M G A, Wagg C. Soil microbial diversity and agro-ecosystem functioning. Plant and Soil, 2013, 363(1/2) : 1-5.

[ 3 ] 钟文辉, 蔡祖聪. 土壤管理措施及环境因素对土壤微生物多样性影响研究进展. 生物多样性, 2004, 12(4): 456-465.

[ 4 ] Burke D J, Weintraub M N, Hewins C R, Kalisz S. Relationship between soil enzyme activities, nutrient cycling and soil fungal communities in a northern hardwood forest. Soil Biology and Biochemistry, 2011, 43(4) : 795-803.

[ 5 ] Jangid K, Williams M A, Franzluebbers A J, Sanderlin J S, Reeves J H, Jenkins M B, Endale D M, Coleman D C, Whitman W B. Relative impacts of land-use, management intensity and fertilization upon soil microbial community structure in agricultural systems. Soil Biology and Biochemistry, 2008, 40(11): 2843-2853.

[ 6 ] Bardgett R D, Van der Putten W H. Belowground biodiversity and ecosystem functioning. Nature, 2014, 515(7528) : 505-511.

[ 7 ] Kennedy A C. Bacterial diversity in agroecosystems. Agriculture, Ecosystems \& Environment, 1999, 74(1/3) : 65-76.

[ 8 ] Liu Y J, Mao L, He X H, Cheng G, Ma X J, An L Z, Feng H Y. Rapid change of AM fungal community in a rain-fed wheat field with short-term plastic film mulching practice. Mycorrhiza, 2012, 22(1): 31-39.

[ 9 ] Hill G T, Mitkowski N A, Aldrich-Wolfe L, Emele L R, Jurkonie D D, Ficke A, Maldonado-Ramirez S, Lynch S T, Nelson E B. Methods for assessing the composition and diversity of soil microbial communities. Applied Soil Ecology, 2000, 15(1) : 25-36.

[10］冯浩, 刘匣, 余坤, 丁奠元, 张浩杰, 褚晓升. 不同覆盖方式对土壤水热与夏玉米生长的影响. 农业机械学报, 2016, 47(12)：192-202.

[11］蔡焕杰，王健，王刘栓. 降雨聚集条件下节水高效农业综合技术. 干旱地区农业研究，1998，16(3): 78-83.

[12] Ren X, Chen X, Jia Z. Effect of rainfall collecting with ridge and furrow on soil moisture and root growth of corn in semiarid Northwest China. Journal of Agronomy and Crop Science, 2010, 196(2): 109-122.

[13] 李玉玲, 张鹏, 张艳, 贾倩民, 刘东华, 董昭芸, 贾志宽, 韩清芳, 任小龙. 旱区集雨种植方式对土壤水分、温度的时空变化及春玉米产 量的影响. 中国农业科学, 2016, 49(6) : 1084-1096.

[14] 胡广荣, 王琦, 宋兴阳, 李富春, 张登奎, 张恩和, 刘青林, 王鹤龄. 沟覆盖材料对垄沟集雨种植土壤温度、作物产量和水分利用效率的 影响. 中国生态农业学报, 2016, 24(5): 590-599.

［15］杨长刚, 柴守胥, 常否. 半干旱雨养区不同覆膜方式对冬小麦土壤水分利用及产量的影响. 生态学报, 2015, 35(8): 2676-2685.

[16] Zhang P, Wei T, Cai T, Ali S, Han Q F, Ren X L, Jia Z K. Plastic-film mulching for enhanced water-use efficiency and economic returns from maize fields in semiarid China. Frontiers in Plant Science, 2017, 8: 512.

[17] Qin W, Hu C S, Oenema O. Soil mulching significantly enhances yields and water and nitrogen use efficiencies of maize and wheat: a metaanalysis. Scientific Reports, 2015, 5(1): 16210.

[18] 陈月星, 温晓霞, 孙瑜琳, 张俊丽, 林晓丽, 廖允成. 地表覆盖对渭北旱作苹果园土壤细菌群落结构及多样性的影响. 微生物学报, 2015, 55(7): 892-904.

[19］董立国, 袁汉民, 李生宝, 袁海燕, 潘占兵. 玉米免耕秸秆覆盖对土壤微生物群落功能多样性的影响. 生态环境学报, 2010, 19(2)： 444-446.

[20] Huang Y L, Chen L S, Fu B J, Huang Z L, Gong J. The wheat yields and water-use efficiency in the Loess Plateau: straw mulch and irrigation effects. Agricultural Water Management, 2005, 72(3): 209-222.

[21］侯晓杰, 汪景宽, 李世朋. 不同施肥处理与地膜覆盖对土壤微生物群落功能多样性的影响. 生态学报, 2007, 27(2): 655-661.

[22] 南京农学院. 土壤农化分析. 北京: 农业出版社, 1980.

[23] Masella A P, Bartram A K, Truszkowski J M, Brown D G, Neufeld J D. PANDAseq: paired-end Assembler for Illumina sequences. BMC Bioinformatics, 2012, 13: 31 .

[24] Edgar R C. UPARSE: highly accurate OTU sequences from microbial amplicon reads. Nature Methods, 2013, 10( 10) : 996-998.

[25] 唐海明, 肖小平, 李超, 汤文光, 郭立君, 汪柯, 孙玉桃, 程凯凯, 孙耿, 潘孝晨. 冬季覆盖作物秸秆还田对双季稻田根际土壤微生物群 落功能多样性的影响. 生态学报, 2018, 38(18): 6559-6569.

[26] 张林森, 刘富庭, 张永旺, 李雪薇, 李丙智, 胥生荣, 谷洁, 韩明玉. 不同覆盖方式对黄土高原地区苹果园土壤有机碳组分及微生物的影 响. 中国农业科学, 2013, 46(15) : 3180-3190.

[27] Williams M A, Rice C W. Seven years of enhanced water availability influences the physiological, structural, and functional attributes of a soil microbial community. Applied Soil Ecology, 2007, 35(3) : 535-545.

［28］孙冰洁, 张晓平, 贾淑霞. 农田土壤理化性质对土壤微生物群落的影响. 土壤与作物, 2013, 2(3): 138-144. 
[29] Delgado-Baquerizo M, Maestre F T, Reich P B, Jeffries T C, Gaitan J J, Encinar D, Berdugo M, Campbell C D, Singh B K. Microbial diversity drives multifunctionality in terrestrial ecosystems. Nature Communications, 2016, 7(1): 10541.

[30] Zhong Y Q W, Yan W M, Wang R W, Wang W, Shangguan Z P. Decreased occurrence of carbon cycle functions in microbial communities along with long-term secondary succession. Soil Biology and Biochemistry, 2018, 123: 207-217.

[31] Wang Y P, Li X G, Fu T T, Wang L, Turner N C, Siddique K H M, Li F M. Multi-site assessment of the effects of plastic-film mulch on the soil organic carbon balance in semiarid areas of China. Agricultural and Forest Meteorology, 2016, 228-229: 42-51.

[32] Paul E A, Clark F E. Soil Microbiology and Biochemistry. 2nd ed. San Diego, CA, USA: Academic Press, 1996.

[33] Zhou J, Jiang X, Zhou B K, Zhao B S, Ma M C, Guan D W, Li J, Chen S F, Cao F M, Shen D L, Qin J. Thirty four years of nitrogen fertilization decreases fungal diversity and alters fungal community composition in black soil in northeast china. Soil Biology and Biochemistry, 2016, 95: 135- 143 .

[34] Rinnan R, Michelsen A, Bååth E, Jonasson S. Fifteen years of climate change manipulations alter soil microbial communities in a subarctic heath ecosystem. Global Change Biology, 2007, 13(1): 28-39.

[35] Simmons C W, Claypool J T, Marshall M N, Jabusch L K, Reddy A P, Simmons B A, Singer S W, Stapleton J J, VanderGheynst J S. Characterization of bacterial communities in solarized soil amended with lignocellulosic organic matter. Applied Soil Ecology, 2014 , 73 : 97-104.

[36] Schonbeck M W, Evanylo G K. Effects of mulches on soil properties and tomato production II. Plant-available nitrogen, organic matter input, and tilth-related properties. Journal of Sustainable Agriculture, 1998, 13(1) : 83-100.

[37] Liu Z F, Fu B J, Zheng X X, Liu G H. Plant biomass, soil water content and soil N: P ratio regulating soil microbial functional diversity in a temperate steppe: a regional scale study. Soil Biology and Biochemistry, 2010, 42(3) : 445-450.

[38] Lynch J M, Whipps J M. Substrate flow in the rhizosphere. Plant and Soil, 1990, 129( 1) : 1- 10.

[39] Miatto R C, Wright I J, Batalha M A. Relationships between soil nutrient status and nutrient-related leaf traits in Brazilian cerrado and seasonal forest communities. Plant and Soil, 2016, 404(1/2): 13-33.

[40] Meng H, Li K, Nie M, Wan J R, Quan Z X, Fang C M, Chen J K, Gu J D, Li B. Responses of bacterial and fungal communities to an elevation gradient in a subtropical montane forest of China. Applied Microbiology and Biotechnology, 2013, 97( 5) : 2219-2230.

[41] 金志薇, 钟文辉, 吴少松, 韩成. 植被退化对滇西北高寒草地土壤微生物群落的影响. 微生物学报, 2018, 58( 12): 2174-2185.

[42] Lipson D A, Schmidt S K. Seasonal Changes in an alpine soil bacterial community in the Colorado rocky mountains. Applied and Environmental Microbiology, 2004, 70(5) : 2867-2879.

[43] Lauber C L, Strickland M S, Bradford M A, Fierer N. The influence of soil properties on the structure of bacterial and fungal communities across land-use types. Soil Biology and Biochemistry, 2008, 40(9): 2407-2415.

[44] Tiwari R, Kumar K, Singh S, Nain L, Shukla P. Molecular detection and environment-specific diversity of glycosyl hydrolase family 1 $\beta$ glucosidase in different habitats. Frontiers in Microbiology, 2016, 7: 1597.

[45] Fierer N, Bradford M A, Jackson R B. Toward an ecological classification of soil bacteria. Ecology, 2007, 88(6) : 1354-1364.

[46] Magill A H, Aber J D. Variation in soil net mineralization rates with dissolved organic carbon additions. Soil Biology and Biochemistry, 2000, 32 (5) : 597-601.

[47] 武俊男, 刘昱辛, 周雪, 王天野, 高强, 高云航, 刘淑霞. 基于 Illumina MiSeq 测序平台分析长期不同施肥处理对黑土真菌群落的影响. 微生物学报, 2018, 58(9): 1658-1671.

[48] Bastida F, Torres I F, Moreno J L, Baldrian P, Ondoño S, Ruiz-Navarro A, Hernández T, Richnow H H, Starke R, García C, Jehmlich N. The active microbial diversity drives ecosystem multifunctionality and is physiologically related to carbon availability in mediterranean semi-arid soils. Molecular Ecology, 2016, 25(18): 4660-4673.

[49] 李瑞霞, 霍艳丽, 李洪杰, 王惟帅, 张爱平, 杨正礼. 氮肥减量对华北夏玉米节根内生真菌群落组成的影响. 农业机械学报, 2018,49 (4) : 312-318.

[50] 田蜜, 陈应龙, 李敏, 刘润进. 丛枝菌根结构与功能研究进展. 应用生态学报, 2013, 24(8): 2369-2376.

[51] Latef A A H A, He C X. Arbuscular mycorrhizal influence on growth, photosynthetic pigments, osmotic adjustment and oxidative stress in tomato plants subjected to low temperature stress. Acta Physiologiae Plantarum, 2011, 33(4) : 1217-1225.

[52］岳英男, 杨春雪. 松嫩盐碱草地土壤理化特性与丛枝菌根真菌侵染的相关性. 草业科学, 2014, 31(8): 1437-1444.

[53] Li J, Xin Z, Yan J, Li H, Chen J, Ding G. Physicochemical and microbiological assessment of soil quality on a chronosequence of a mine reclamation site. European Journal of Soil Science, 2018, 69(6) : 1056-1067. 